\title{
The Role of Hydrogen Bonding on Laminar Burning Velocity of Hydrous and Anhydrous Ethanol Fuel with Small Addition of n-Heptane
}

\author{
I Made Suarta, ${ }^{1,2}$ I. N. G. Wardana, ${ }^{2}$ Nurkholis Hamidi, ${ }^{2}$ and Widya Wijayanti ${ }^{2}$ \\ ${ }^{1}$ Mechanical Engineering Department, Bali State Polytechnic, Badung, Bali 80361, Indonesia \\ ${ }^{2}$ Department of Mechanical Engineering, Brawijaya University, Malang, East Java, Indonesia \\ Correspondence should be addressed to I Made Suarta; suarta_bedil@yahoo.com
}

Received 27 June 2016; Revised 5 October 2016; Accepted 11 October 2016

Academic Editor: Hong G. Im

Copyright (C) 2016 I Made Suarta et al. This is an open access article distributed under the Creative Commons Attribution License, which permits unrestricted use, distribution, and reproduction in any medium, provided the original work is properly cited.

\begin{abstract}
The molecular structure of mixed hydrous and anhydrous ethanol with up to $10 \% \mathrm{v} n$-heptane had been studied. The burning velocity was examined in a cylindrical explosion combustion chamber. The result showed that the burning velocity of hydrous ethanol is higher than anhydrous ethanol and n-heptane at stoichiometric, rich, and very rich mixtures. The burning velocity of hydrous ethanol with $n$-heptane drops drastically compared to the burning velocity of anhydrous ethanol with n-heptane. It is caused by two reasons. Firstly, there was a composition change of azeotropic hydrous ethanol molecules within the mixture of fuel. Secondly, at the same volume the number of ethanol molecules in hydrous ethanol was less than in anhydrous ethanol at the same composition of the $\mathrm{n}$-heptane in the mixture. At the mixture of anhydrous ethanol with $\mathrm{n}$-heptane, the burning velocity decreases proportionally to the addition of the $\mathrm{n}$-heptane composition. The burning velocity is between the velocities of anhydrous ethanol and n-heptane. It shows that the burning velocity of anhydrous ethanol mixed with $\mathrm{n}$-heptane is only influenced by the mixture composition.
\end{abstract}

\section{Introduction}

Combustion is the best way to obtain large amounts of energy in a short time. Burning velocity is the most important parameter in the fuel combustion process, of either external or internal combustion engines. The burning velocity is influenced by several factors like fuel, air fuel ratio, and onset combustion pressure and temperature.

Hydrous ethanol $(4.0-4.9 \% \mathrm{v}$ of water) is intensively developed as fuel due to its characteristics like being renewable, having low $\mathrm{NO}_{x}$ emission, increasing engine working pressures, and reducing production cost [1-4]. In Brazil, FlexFuel vehicles that can be operated with $100 \%$ hydrous ethanol have been in the market since 2003. In the vehicles, ethanol can be used separately as fuel or combined with gasoline as the octane enhancer and oxygenate.

The $\mathrm{n}$-heptane is one of the fuel main references [5]. The mixture of $n$-heptane and isooctane is considered as the major component of gasoline. This combination at any number of octane has also been researched for many times.
Unfortunately, either n-heptane or isooctane is fossil fuel in which it is nonrenewable energy.

Nowadays, since the issues on the fossil fuel stock and environment are oftentimes discussed, this increases the interest in using the alternative-renewable fuel that is also good for environment. Hydrous and anhydrous ethanol are renewable fuel with the higher octane number compared to isooctane. Until today, hydrous ethanol is considered as candidate to be set as additive or even substitution for the fossil fuel. It is because hydrous ethanol can be easily combined with hydrocarbon and produced by simple process.

The burning velocity of the mixture of n-heptane and ethanol had been observed by $[6,7]$. Their results showed that the burning velocity of ethanol is higher than $n$-heptane at either the lean, stoichiometric, or rich mixtures. The burning velocity of $n$-heptane and ethanol is among those two [6]. The results of [7] showed that the addition of alcohol does not cause the decomposition of hydrocarbon. The addition of alcohol on $\mathrm{n}$-heptane gave a little effect to the fuel's chemical interaction. 


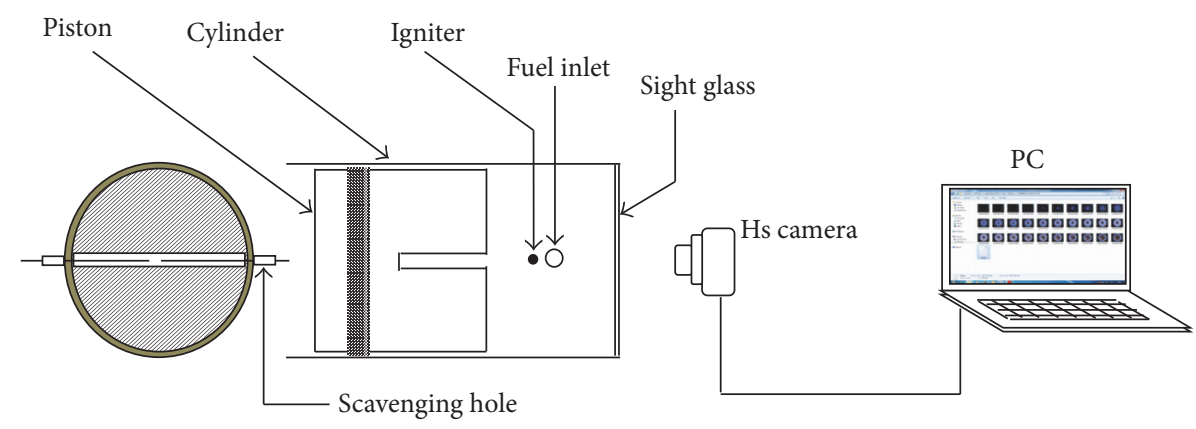

FIGURE 1: Experimental setup.

The examination of the mixture of ethanol and n-heptane used directly as fuel for engine has been executed by [811]. The study of [8] denoted that alcohol has a better prospect within engines since it possesses higher latent heat of evaporation and larger number of oxygen molecules. The result of [9] showed that when the system uses ethanol/nheptane fuel, the ignition delay increases very high but the temperature and pressure in the cylinder decrease drastically in a higher ratio. But, based on some existing studies, there is no fundamental data covering the premixed combustion behavior of hydrous and anhydrous ethanol with n-heptane, especially the ones related to laminar burning velocity.

Therefore, the objective of this study is to acquire new data about laminar burning velocity of the mixtures of anhydrous ethanol $(99.7 \% \mathrm{v})$ and hydrous ethanol $(95.5 \% \mathrm{v})$ with $\mathrm{n}$-heptane in varied composition at lean $(\phi=0.9)$, stoichiometric $(\phi=1)$, rich $(\phi=1.1)$, and very rich mixture $(\phi=1.2)$. It is motivated by the characteristics of hydrous ethanol fuel which is better than anhydrous ethanol at the stoichiometric and rich mixture [12]. The mixture of ethanol/nheptane can combine the renewable fuel with fossil fuel.

\section{Experiment Design, Procedure, and Data Analysis}

The premixed combustion of hydrous and anhydrous ethanol mixed with n-heptane was observed in a cylindrical explosion combustion chamber as shown in Figure 1. Its diameter is $135 \mathrm{~mm}$ and the length is $270 \mathrm{~mm}$. This model had also been used in [13-16]. The frontal end of the chamber was closed with transparent glass wall for capturing the fireball growth with a high speed camera. The other end was a piston which could move freely during the development of fireball. The left side wall of the cylinder was fitted with positive $(+)$ terminal of an igniter and fuel inlet for insertion of fuel mixture, while the right side was negative $(-)$ igniter and scavenging manifold.

Anhydrous ethanol with purity of $99.7 \% \mathrm{v}$ was used as fuel and hydrous ethanol of $95.5 \% \mathrm{v}$ was made in the analytical chemical laboratory. The test was conducted at atmospheric pressure and room temperature at $303 \mathrm{~K}$.

Liquid hydrous ethanol fuels and air are introduced into the mixing chamber at the desired equivalence ratio. After that, the latent heat for evaporation of the fuels was supplied by blowing air to the surface of mixing chamber at room temperature so it turns into the gas state. The mixture was put into the combustion chamber to test its burning velocity. Flame radius was visualized from the frontal end of the combustion chamber. Before igniting, the camera was firstly turned on and set up at a speed of $420 \mathrm{fps}$.

\section{Data Processing}

Broustail et al. [13], Beeckmann et al. [14], Zhang et al. [15], and Johnston and Farrell [16] studied the characteristic of laminar burning velocity from a variety of fuels in spherical combustion bomb and developed a theory of developing flame ball. According to this theory, the stretched laminar flame propagation speed $\left(S_{n}\right)$ can be calculated from the growth rate of flame radius as

$$
S_{n}=\frac{d r}{d t}
$$

in which $r$ is the radius of spherical flame front and $t$ is the time when the radius is measured. The stretched rate $(\alpha)$ of spherical flame is obtained at any captured image on the flame surface [12], as follows:

$$
\alpha=\frac{d(\ln A)}{d t}=\frac{d A / A}{d t}=\frac{d A}{A \cdot d t}
$$

in which $A$ is the surface area of the flame. In the case of spherical propagating flame, the flame stretched rate can be calculated as

$$
\alpha=\frac{d A}{A \cdot d t}=\left(\frac{2}{r}\right)\left(\frac{d r}{d t}\right)=\left(\frac{2}{r}\right) S_{n} .
$$

A linear relationship between the unstretched flame speed $\left(S_{s}\right)$ and stretched flame speed has been reported in [1517] as

$$
S_{s}-S_{n}=L_{b} \cdot \alpha
$$

Based on (4), it can be seen that $S_{s}$ is the same with $S_{n}$ when $\alpha=0$.

Laminar burning velocity $\left(S_{L}\right)$ is derived from $S_{s}$ as

$$
S_{L}=\frac{\rho_{b}}{\rho_{u}} S_{s} .
$$



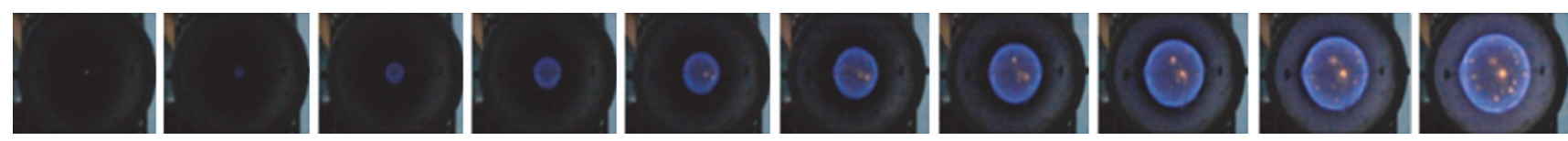

(a)
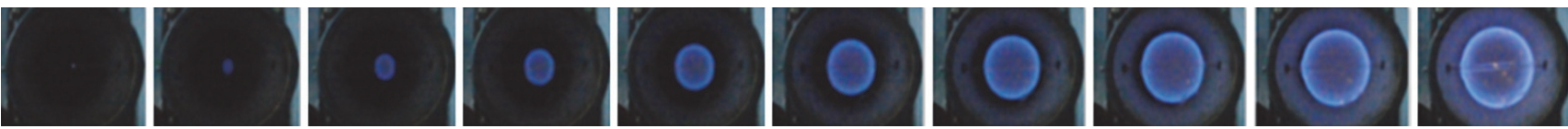

(b)
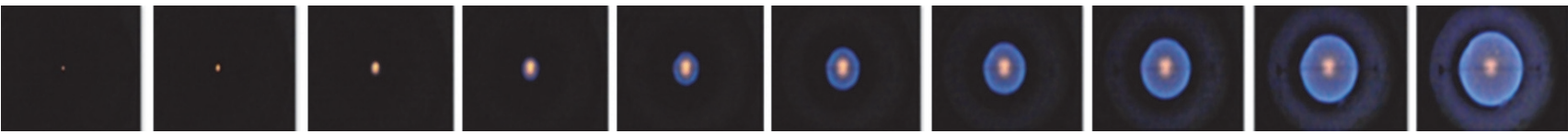

(c)

FiguRE 2: Typical growing image of flame radius with time interval of $2.381 \mathrm{~ms}(\phi=1.1, T=305 \mathrm{~K}$, and $P=1 \mathrm{~atm})$ for (a) hydrous ethanol $(95.5 \% \mathrm{v})$; (b) anhydrous ethanol $(99.7 \% \mathrm{v})$; (c) n-heptane.

$\rho_{b}$ and $\rho_{u}$ are, respectively, the density of combustion gases and the density of the reactants. $\rho_{b}$ is calculated at adiabatic flame temperature.

\section{Results and Discussion}

Laminar burning velocity of hydrous and anhydrous ethanol and their respective mixture with $n$-heptane had been measured from flame images at any equivalence ratio $(\phi)$, fuel heating value, and adiabatic flame temperature in which all of them were affected by the addition of $n$-heptane and water content of the fuel.

Low Heating Value (LHV) of hydrous ethanol was determined based on the water content in the ethanol. LHV of hydrous ethanol was obtained by multiplying the mass percentage of hydrous ethanol with LHV of anhydrous ethanol in which its value is $26.8 \mathrm{MJ} / \mathrm{kg}$. The LHV of n-heptane is $44.50 \mathrm{MJ} / \mathrm{kg}[8,9]$. Meanwhile, LHV of the mixture of hydrous and anhydrous ethanol with $\mathrm{n}$-heptane was obtained by averaging both LHV values of those fuels. The adiabatic flame temperature was calculated using the formula in [18].

4.1. The Pure Fuel Laminar Burning Velocity. When the mixture of fuel and air had been filled into the combustion chamber, the sparker (igniter) was ignited in the middle of combustion chamber, and the fire then spread towards reactant in the direction of combustion chamber's radius. Figure 2 shows the development of the fireball of hydrous ethanol, anhydrous ethanol, and n-heptane with the increase of diameter at each $2.381 \mathrm{~ms}$.

The flame front was determined by using color differences which occur between the color of fire (bright blue) and reactants color (dark blue) as shown in Figure 3 which shows the photo of flame ethanol $95.5 \% \mathrm{v}$, at $\phi=1$ after $23.81 \mathrm{~ms}$ from the ignition. Good quality pictures could be taken in this experiment due to a good blocking of the outside light from the environment to the apparatus. The light from the environment was blocked so that the border between the

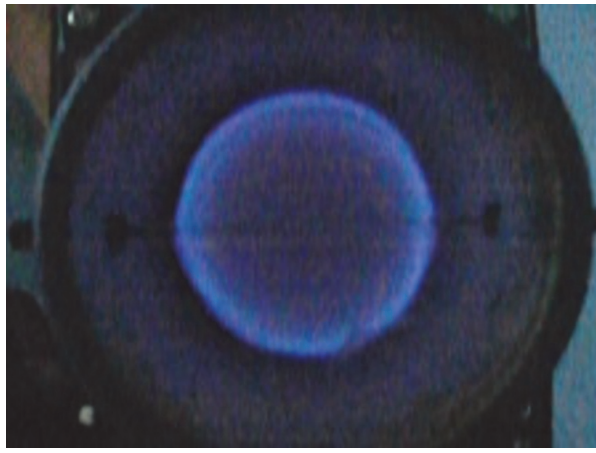

FIGURE 3: Photo of flame ethanol $95.5 \% \mathrm{v}$; at $\phi=1$ after $23.81 \mathrm{~ms}$.

surface of fire and the reactants is very thin, less than $1 \%$ of the flame radius. This means that there is almost no significant measurement error on flame radius $(r)$.

From Figure 2, the stretched flame speed $\left(S_{n}\right)$ could be determined by using formula (1). Unstretched flame speed $\left(S_{s}\right)$ was obtained by extrapolating the value of $S_{n}$ at $\alpha=0$. Figure 4 shows $S_{s}$ for hydrous ethanol, anhydrous ethanol, and n-heptane at stoichiometric, rich, and very rich mixture. It is seen that $S_{s}$ at the very rich mixture is higher than at the rich and stoichiometric mixture.

By using (5), each fuel's laminar burning velocity $\left(S_{L}\right)$ can be determined. Figure 5 shows $S_{L}$ of each fuel. $S_{L}$ of hydrous ethanol is higher than anhydrous ethanol and n-heptane at the stoichiometric and rich mixture. Though the calorific value of hydrous ethanol is lower than anhydrous ethanol and n-heptane, and since the molecular structure of hydrous ethanol is shorter, with a centered oxygenate, the burning velocity increases.

4.2. The Effect of n-Heptane Blending to Hydrous and Anhydrous Ethanol on Laminar Burning Velocity. Figure 6 shows the value of $S_{s}$ for hydrous and anhydrous ethanol fuel mixed with n-heptane. The legend $95.5+2$ means ethanol $95.5 \% \mathrm{v}$ 

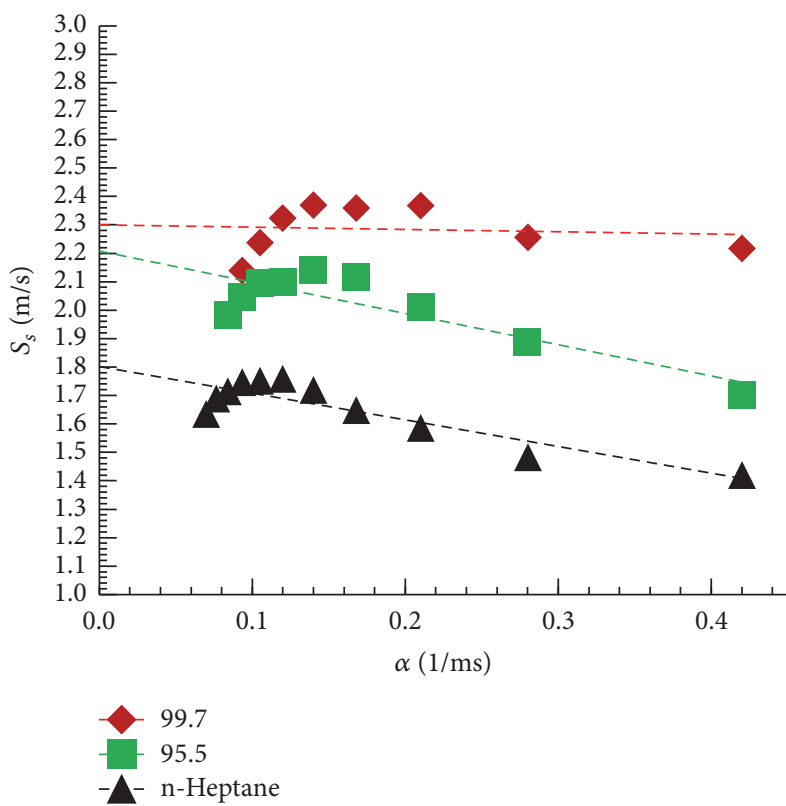

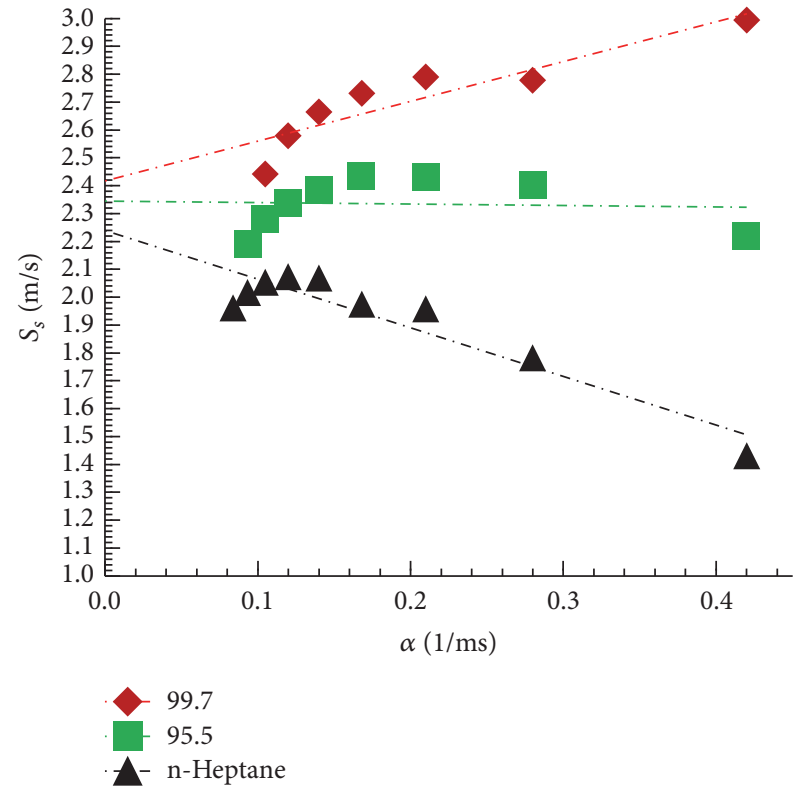

(b)

(a)

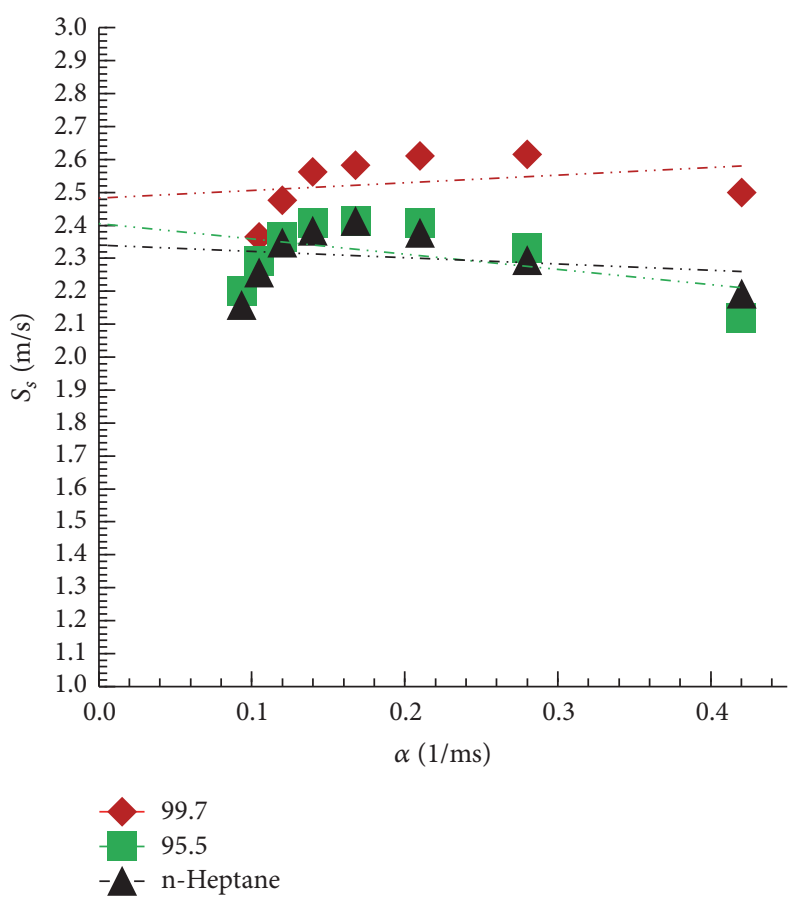

(c)

FIGURE 4: Flame stretch rate for the hydrous ethanol, anhydrous ethanol, and n-heptane. (a) Stoichiometric mixture; (b) rich mixture; (c) very rich mixture.

was added with $2 \% \mathrm{v}$ of $\mathrm{n}$-heptane. The $99.7+2$ means ethanol $99.7 \% \mathrm{v}$ was added with $2 \% \mathrm{v}$ of $\mathrm{n}$-heptane. In Figure 6(a), it is shown that there is a very significant change of flame speed after the hydrous ethanol was added with $2 \% \mathrm{v}$ of $\mathrm{n}$-heptane. The increasing percentage of $n$-heptane, furthermore, up to $10 \% \mathrm{v}$ reduced the speed proportionally to the increase of $\mathrm{n}$ heptane.

In Figure 6(b), it is shown that there is a decreasing value of $S_{s}$ after the anhydrous ethanol was mixed with n-heptane.
$S_{s}$ decreases proportionally to the addition of n-heptane. $S_{s}$ of mixed fuel is between $S_{s}$ of pure anhydrous ethanol and $S_{s}$ of n-heptane.

When compared with the data of Bradley et al. [19] for anhydrous ethanol containing very small liquid phase with liquid droplet of diameter $31 \mu \mathrm{m}$, the trend of the data agrees very well (see Figure 7). Differences in flame speed between this study and that of [19] can be caused by several factors such as measurements, temperature, and research apparatus 


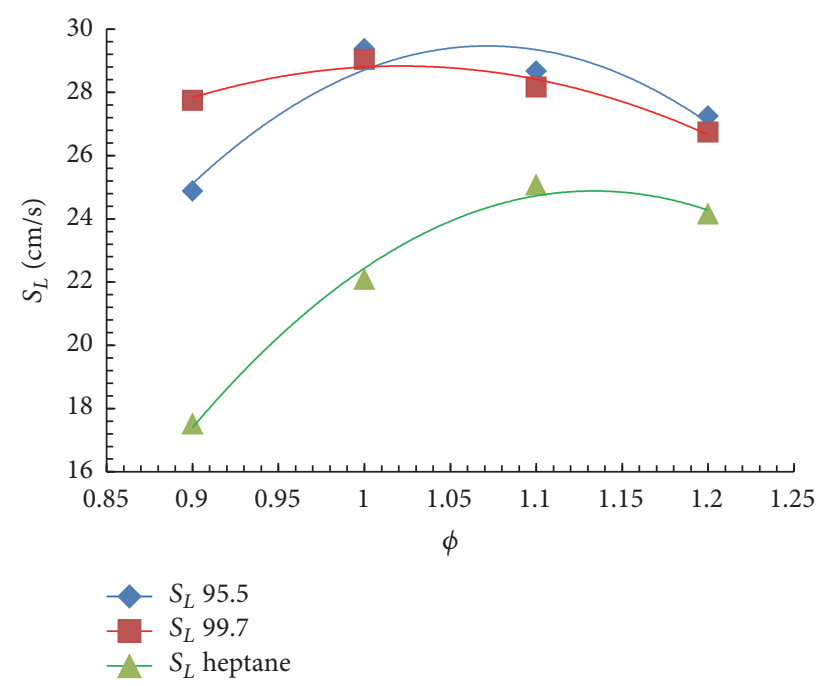

FIGURE 5: Laminar burning velocity of hydrous ethanol, anhydrous ethanol, and n-heptane fuels.

factors. For measurements, the error in this study is very small, less than $1 \%$. For the temperature, all studies were conducted at room temperature which has low possibility of providing a difference in the results. Then, the difference is considered to come from the research apparatus factor. There was little friction between the piston and the cylinder in the combustion chamber of current research that led to a slight increase in pressure that decreases the speed of combustion, compared with research conducted by Bradley without piston.

There are limitations to doing experiment at equivalent ratio $(\phi)$ below 0.9 and above 1.2. At $\phi<0.9$, because the fuel contains a small amount of water, the calorific value of the fuel is very low and the water in the fuel absorbs energy so that reactants become difficult to be ignited. At $\phi>1.2$ the fuel is too saturated so it is difficult to evaporate it in the mixing chamber because the reactants quickly turn into droplets that cause the mixture to become nonhomogeneous.

The burning velocity, $S_{L}$, of hydrous and anhydrous ethanol mixed with $n$-heptane on each equivalence ratio can be seen in Figure 8. In Figure 8(a), it is shown that $S_{L}$ for hydrous ethanol drastically drops after being added with $2 \% \mathrm{~V}$ of $\mathrm{n}$-heptane. The further addition of $\mathrm{n}$-heptane up to $10 \% \mathrm{v}$ reduces the laminar burning velocity, proportionally to the increasing of n-heptane volume.

$S_{L}$ of anhydrous ethanol mixed with $\mathrm{n}$-heptane decreases from $S_{L}$ of ethanol. The burning velocity of the mixed fuel is between $S_{L}$ of anhydrous ethanol and n-heptane. The burning velocity decreases proportionally to the increasing volume of n-heptane can be seen in Figure 8(b).

\section{Discussion}

The burning velocity of a fuel is highly influenced by heat value, length of the chain, and molecular structure of the fuel. A shorter carbon chain in the fuel will increase the burning velocity [20]. In the previous study, Suarta et al.

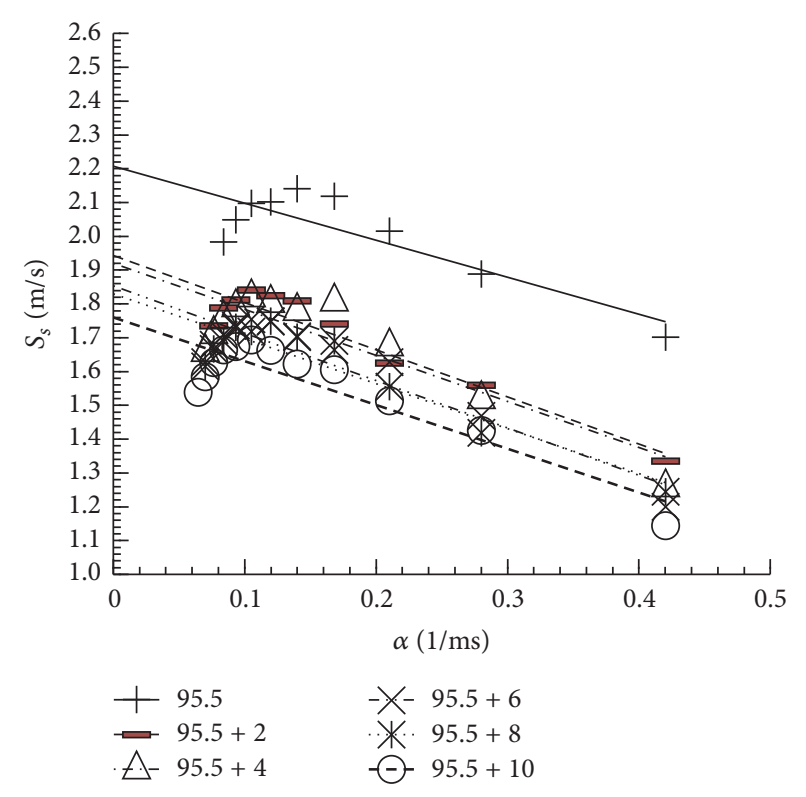

(a)

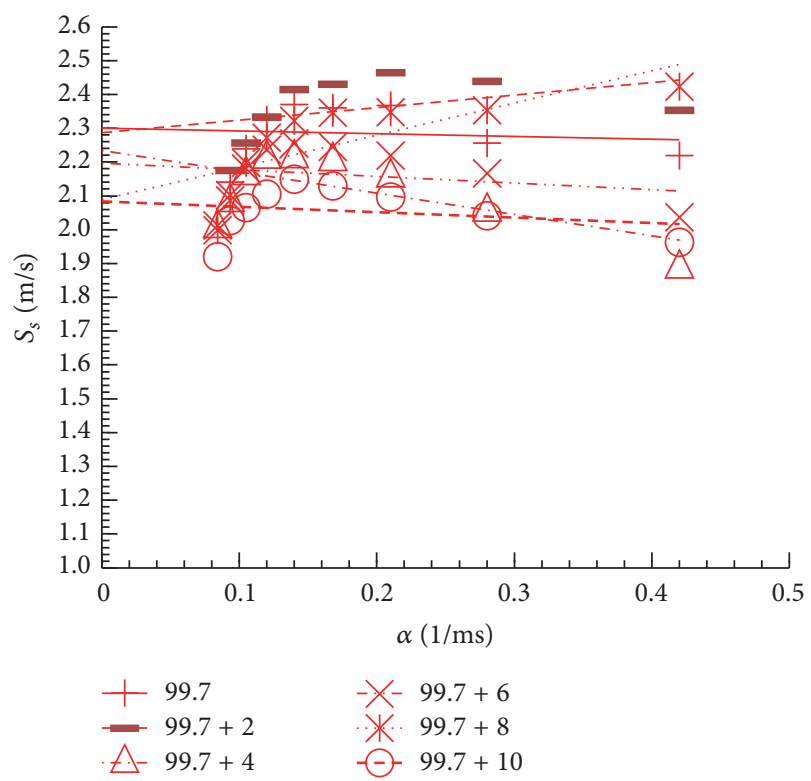

(b)

Figure 6: The flame speed for the stretch at $\phi=1$. (a) Hydrous ethanol is added with n-heptane. (b) Anhydrous ethanol is added with n-heptane.

[12] showed that the composition of azeotropic hydrous ethanol occurs at a $95.1 \% \mathrm{v}$ composition with the molecular structure as in Figure 9(a). The maximum burning velocity of hydrous ethanol occurs at a $95.5 \% \mathrm{v}$ composition with the molecular structure as in Figure 9(b). The molecular structure of anhydrous ethanol is in Figure 9(c) and the molecular structure of $n$-heptane is in Figure 9(d).

The laminar burning velocity of hydrous ethanol decreased drastically with the addition of n-heptane. It was caused by the composition change of azeotropic group within the fuel. The presence of $n$-heptane molecule within the 


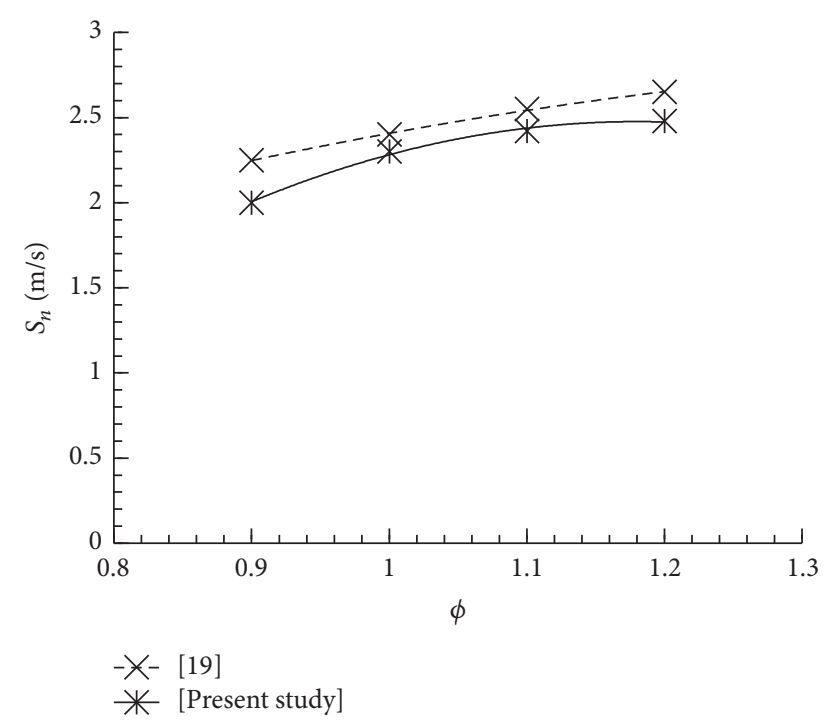

FIgURE 7: Comparison of the value of $S_{s}$ for anhydrous ethanol between [19] and present study.

$95.5 \% \mathrm{v}$ of hydrous ethanol fuel elevates the calorific value but there would be a molecule that disrupts its azeotropic characteristic.

From the molecular structure point of view, when hydrous ethanol $95.5 \% \mathrm{v}$ is added with $8 \% \mathrm{v}$ of $\mathrm{n}$-heptane, then, in the mixed fuel, there will be two molecules of ethanol $95.5 \% \mathrm{v}$ and one $\mathrm{n}$-heptane molecule. This composition can be said as 4 azeotropic molecules $(95.1 \% \mathrm{v})$ with two free ethanol molecules and one n-heptane molecule. This composition is depicted in Figure 10.

The presence of $n$-heptane would disrupt the azeotropic characteristic. The burning velocity of hydrous ethanol with h-heptane decreased drastically from the velocity of hydrous ethanol.

The burning velocity of anhydrous ethanol decreased with the addition of $\mathrm{n}$-heptane. The burning velocity decreased proportionally to the addition of $\% \mathrm{v}$ of $n$-heptane as shown in Figure 8(b). The burning velocity is between the burning velocity of anhydrous ethanol and n-heptane. It is caused by the chain of anhydrous ethanol that has hydrogen bond which becomes a long chain having structure almost similar to the chain of $\mathrm{n}$-heptane. Thus, the burning velocity is only influenced by the burning velocity of each fuel. From molecular structure shown in Figure 11, it is seen that when anhydrous ethanol is added with $8 \% \mathrm{v}$ of $\mathrm{n}$-heptane then, in 29 molecules of ethanol, there is only one n-heptane molecule. It is also declared in [7] that the addition of alcohol does not influence the decomposition of hydrocarbon fuel.

The addition of $\mathrm{n}$-heptane on hydrous ethanol of $95.5 \% \mathrm{v}$ caused a very sharp decrease of velocity, compared to the addition on anhydrous ethanol. It is because of the different number of ethanol molecules. In hydrous ethanol, the number of ethanol molecules is less than the number of anhydrous ethanol molecules in the same mixture ratio with n-heptane. It can be seen from molecular structures in Figure 10 that, with $8 \% \mathrm{v}$ of $\mathrm{n}$-heptane, at hydrous ethanol of $95.5 \% \mathrm{v}$, there

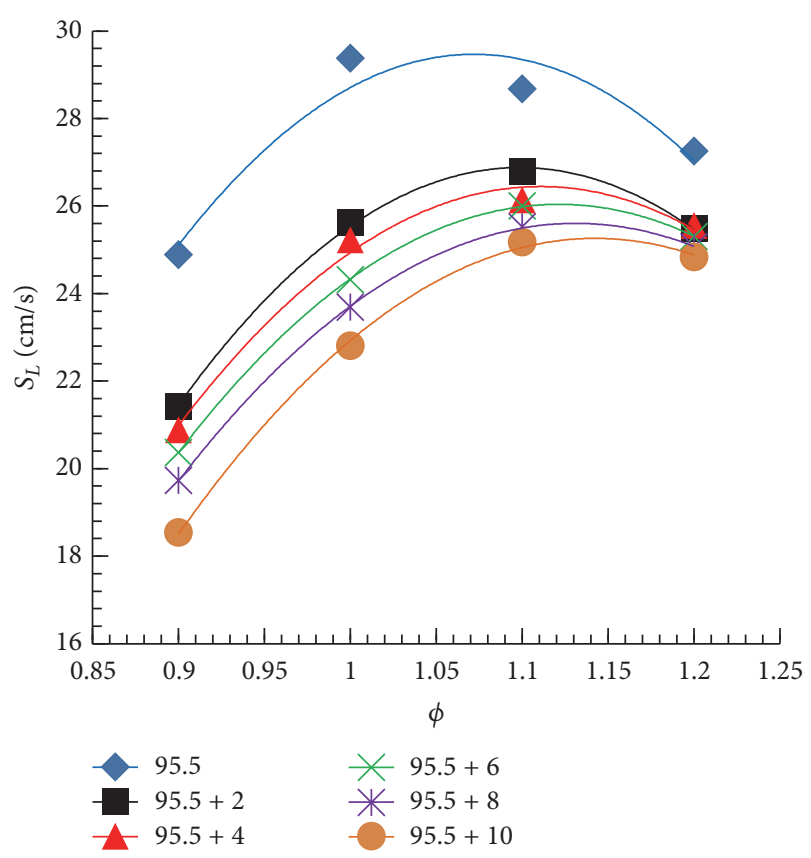

(a)

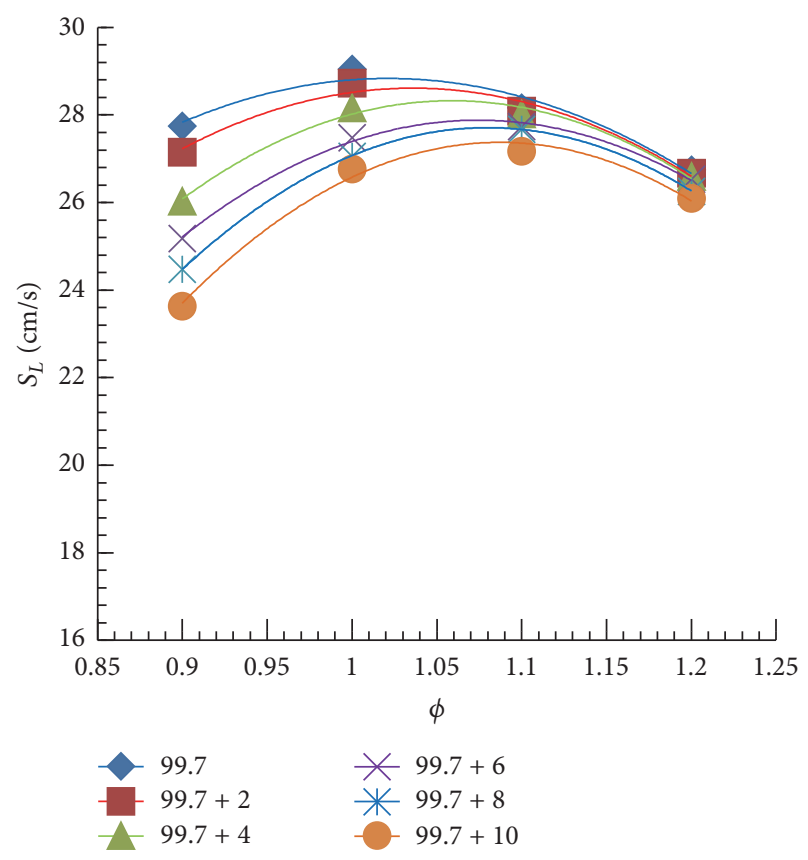

(b)

FIGURE 8: Laminar burning velocity of ethanol and its mixture with n-heptane. (a) Hydrous ethanol; (b) anhydrous ethanol.

are 26 ethanol molecules that have calorific value with four water molecules that do not have calorific value. The azeotropic characteristic with centered oxygenate is very disrupted by the presence of $\mathrm{n}$-heptane. Meanwhile, at the anhydrous ethanol added with $8 \%$ of n-heptane (Figure 11), there are 29 ethanol molecules and one $\mathrm{n}$-heptane molecule. Besides the larger number of ethanol molecules, the same molecule structure causes the decrease of velocity to be 


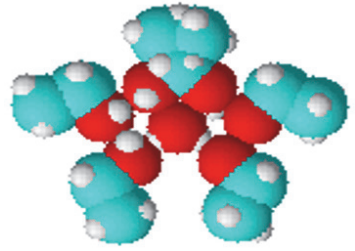

(a)

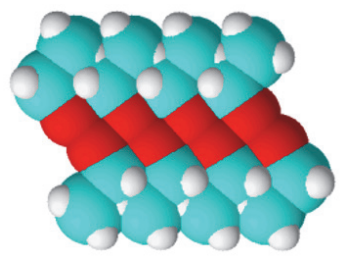

(c)

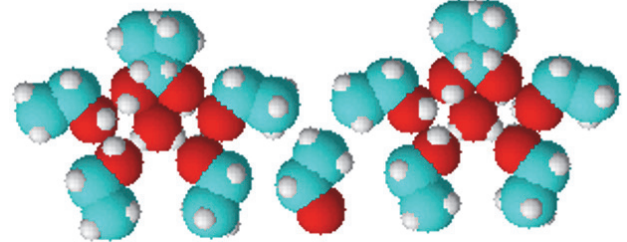

(b)

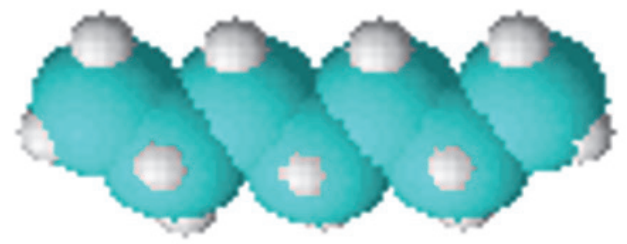

(d)

FIgURE 9: The molecular structure of (a) azeotropic ethanol; (b) ethanol of 95.5\% v; (c) anhydrous ethanol; (d) n-heptane.
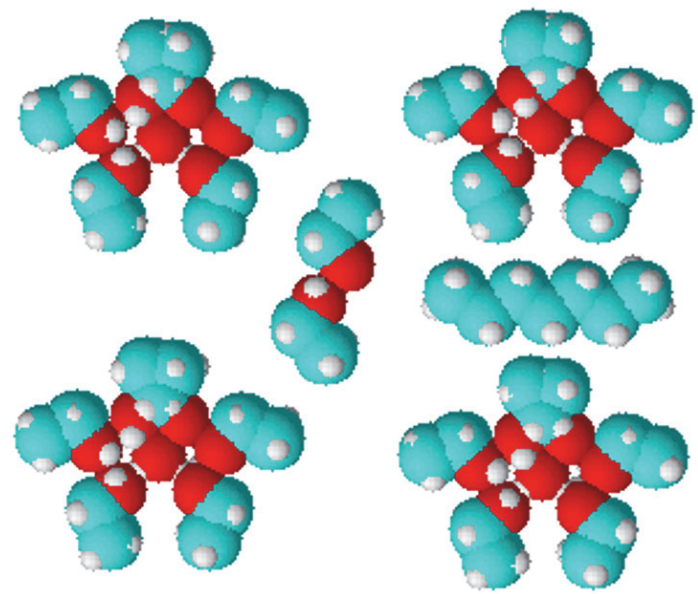

FIGURE 10: The molecular structure of ethanol $95.5 \% \mathrm{v}$ being added with $8 \% \mathrm{v}$ n-heptane.

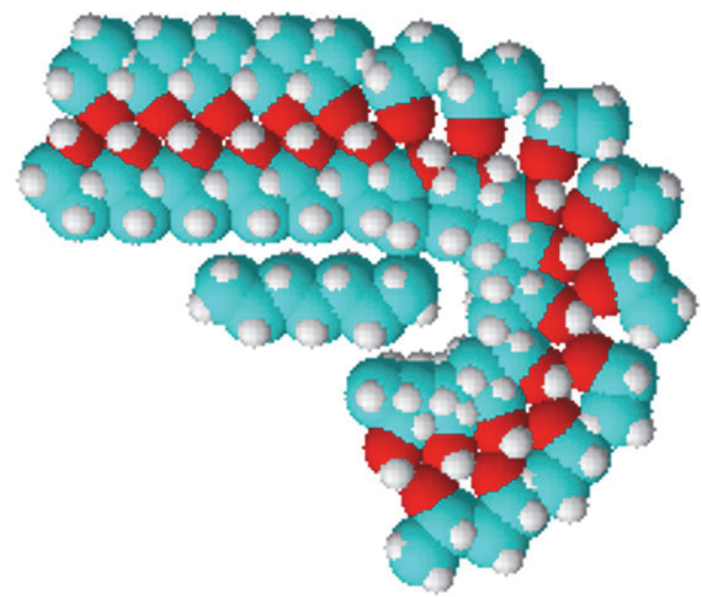

FIGURE 11: Molecular structure of anhydrous ethanol being added with $8 \% \mathrm{v}$ of $\mathrm{n}$-heptane. between the burning velocities of each fuel. Or it decreases proportionally to the addition of the volume of $n$-heptane.

\section{Conclusion}

From the comparison between premixed combustion of hydrous ethanol with $\mathrm{n}$-heptane and that of anhydrous ethanol with n-heptane, there are some conclusions gathered as follows:

(i) Without the addition of $n$-heptane, the burning velocity of hydrous ethanol is higher than anhydrous ethanol and $\mathrm{n}$-heptane.

(ii) The burning velocity of hydrous ethanol decreases drastically with the addition of $n$-heptane.

(iii) The burning velocity of anhydrous ethanol with $\mathrm{n}$ heptane is between the velocities of each fuel, depending on the composition.

(iv) Hydrous ethanol is better to be used as pure fuel so that its azeotropic molecular structure is not disrupted.

\section{Competing Interests}

The authors declare that they have no competing interests.

\section{Acknowledgments}

The authors would like acknowledge the Directorate of Indonesia Higher Education for Research and Community Service, no. 093/SP2H/LT/DRPM/II/2016, for the financial support to this project.

\section{References}

[1] S. Saxena, S. Schneider, S. Aceves, and R. Dibble, "Wet ethanol in HCCI engines with exhaust heat recovery to improve the 
energy balance of ethanol fuels," Applied Energy, vol. 98, pp. 448-457, 2012.

[2] T. C. C. de Melo, G. B. MacHado, C. R. P. Belchior et al., "Hydrous ethanol-gasoline blends-combustion and emission investigations on a Flex-Fuel engine," Fuel, vol. 97, pp. 796-804, 2012.

[3] I. Schifter, L. Diaz, J. P. Gómez, and U. Gonzalez, "Combustion characterization in a single cylinder engine with mid-level hydrated ethanol-gasoline blended fuels," Fuel, vol. 103, pp. 292298, 2013.

[4] R. C. Costa and J. R. Sodré, "Hydrous ethanol vs. gasolineethanol blend: engine performance and emissions," Fuel, vol. 89, no. 2, pp. 287-293, 2010.

[5] G. Chen, W. Yu, J. Fu et al., "Experimental and modeling study of the effects of adding oxygenated fuels to premixed n-heptane flames," Combustion and Flame, vol. 159, no. 7, pp. 2324-2335, 2012.

[6] J. P. J. Van Lipzig, E. J. K. Nilsson, L. P. H. De Goey, and A. A. Konnov, "Laminar burning velocities of n-heptane, iso-octane, ethanol and their binary and tertiary mixtures," Fuel, vol. 90, no. 8, pp. 2773-2781, 2011.

[7] H. Xu, C. Yao, G. Xu, Z. Wang, and H. Jin, "Experimental and modelling studies of the effects of methanol and ethanol addition on the laminar premixed low-pressure n-heptane/toluene flames," Combustion and Flame, vol. 160, no. 8, pp. 1333-1344, 2013.

[8] Y. Qian, L. Ouyang, X. Wang, L. Zhu, and X. Lu, "Experimental studies on combustion and emissions of RCCI fueled with nheptane/alcohols fuels," Fuel, vol. 162, pp. 239-250, 2015.

[9] Y. Qian, X. Wang, L. Zhu, and X. Lu, "Experimental studies on combustion and emissions of RCCI (reactivity controlled compression ignition) with gasoline/n-heptane and ethanol/nheptane as fuels," Energy, vol. 88, pp. 584-594, 2015.

[10] P. Saisirirat, C. Togbé, S. Chanchaona, F. Foucher, C. MounaimRousselle, and P. Dagaut, "Auto-ignition and combustion characteristics in HCCI and JSR using 1-butanol/n-heptane and ethanol/n-heptane blends," Proceedings of the Combustion Institute, vol. 33, no. 2, pp. 3007-3014, 2011.

[11] D. Vuilleumier, D. Kozarac, M. Mehl et al., "Intermediate temperature heat release in an HCCI engine fueled by ethanol/nheptane mixtures: an experimental and modeling study," Combustion and Flame, vol. 161, no. 3, pp. 680-695, 2014.

[12] I. M. Suarta, I. N. Wardana, N. Hamidi, and W. Wijayanti, "The role of molecule clustering by hydrogen bond in hydrous ethanol on laminar burning velocity," Journal of Combustion, vol. 2016, Article ID 5127682, 9 pages, 2016.

[13] G. Broustail, P. Seers, F. Halter, G. Moréac, and C. MounaimRousselle, "Experimental determination of laminar burning velocity for butanol and ethanol iso-octane blends," Fuel, vol. 90, no. 1, pp. 1-6, 2011.

[14] J. Beeckmann, L. Cai, and H. Pitsch, "Experimental investigation of the laminar burning velocities of methanol, ethanol, $n$ propanol, and n-butanol at high pressure," Fuel, vol. 117, pp. 340350, 2014.

[15] Z. Zhang, G. Li, L. Ouyang, Z. Pan, F. You, and X. Gao, "Experimental determination of laminar burning velocities and Markstein lengths for 75\% hydrous-ethanol, hydrogen and air gaseous mixtures,' International Journal of Hydrogen Energy, vol. 36, no. 20, pp. 13194-13206, 2011.

[16] R. J. Johnston and J. T. Farrell, "Laminar burning velocities and Markstein lengths of aromatics at elevated temperature and pressure," Proceedings of the Combustion Institute, vol. 30, no. 1, pp. 217-224, 2005.

[17] X. Qin and Y. Ju, "Measurements of burning velocities of dimethyl ether and air premixed flames at elevated pressures," Proceedings of the Combustion Institute, vol. 30, no. 1, pp. 233240, 2015.

[18] J. M. Smith, H. C. Van Ness, and M. M. Abbott, Introduction to Chemical Engineering Thermodynamics, McGraw-Hill, New York, NY, USA, 2001.

[19] D. Bradley, M. Lawes, S. Liao, and A. Saat, "Laminar mass burning and entrainment velocities and flame instabilities of ioctane, ethanol and hydrous ethanol/air aerosols," Combustion and Flame, vol. 161, no. 6, pp. 1620-1632, 2014.

[20] E. Ranzi, A. Frassoldati, R. Grana et al., "Hierarchical and comparative kinetic modeling of laminar flame speeds of hydrocarbon and oxygenated fuels," Progress in Energy and Combustion Science, vol. 38, no. 4, pp. 468-501, 2012. 


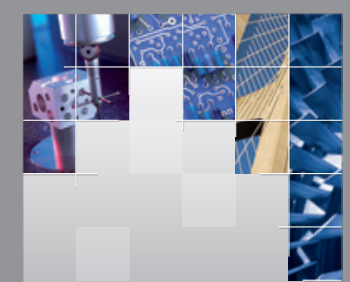

\section{Enfincering}
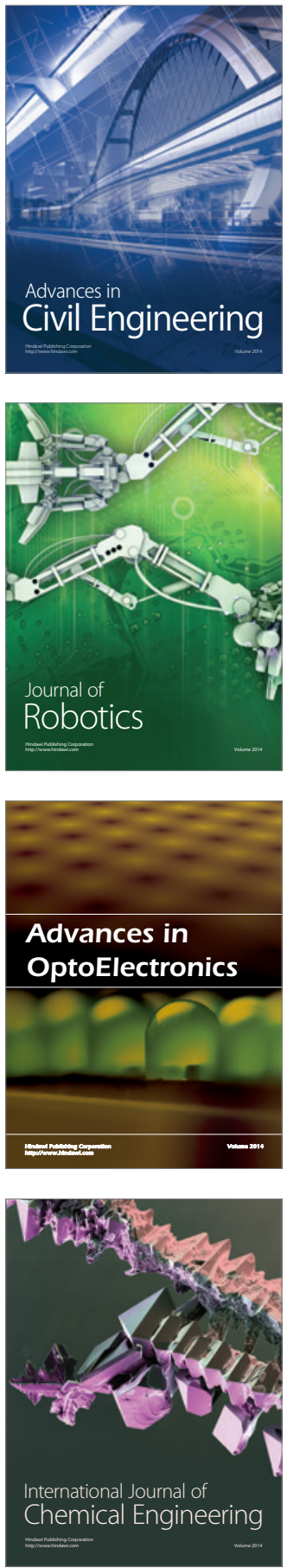

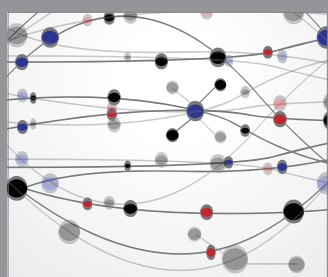

The Scientific World Journal

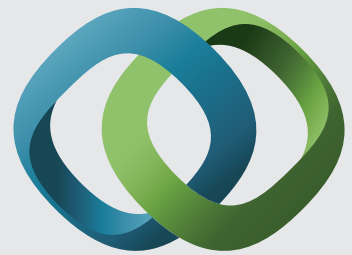

\section{Hindawi}

Submit your manuscripts at

http://www.hindawi.com
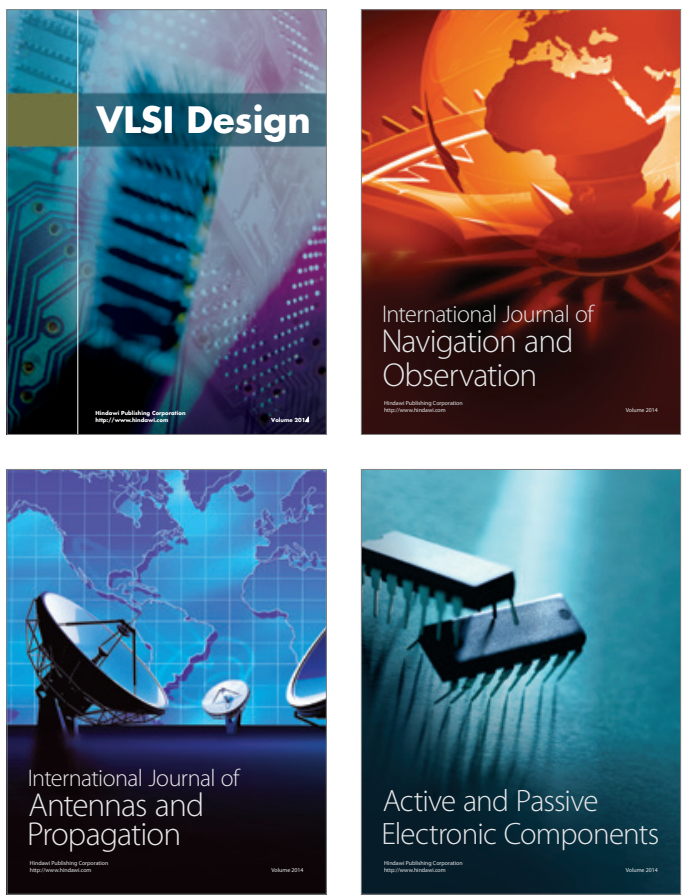
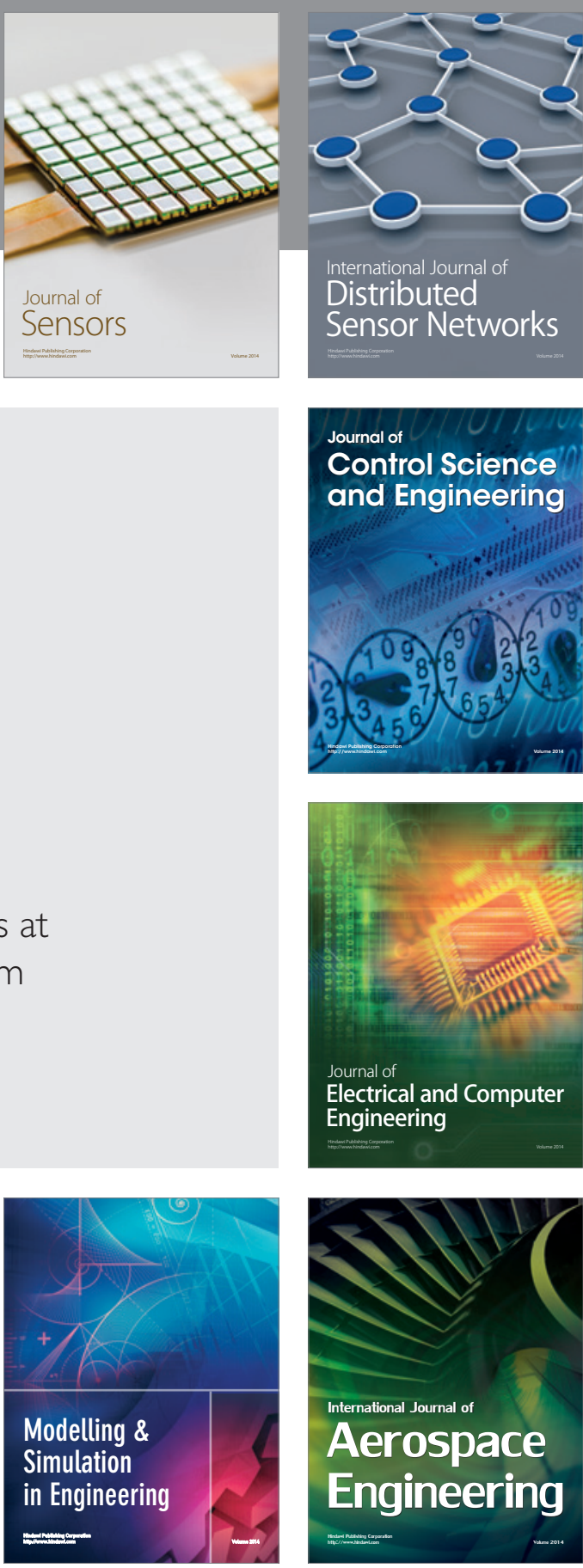

International Journal of

Distributed

Sensor Networks

Journal of

Control Science

and Engineering
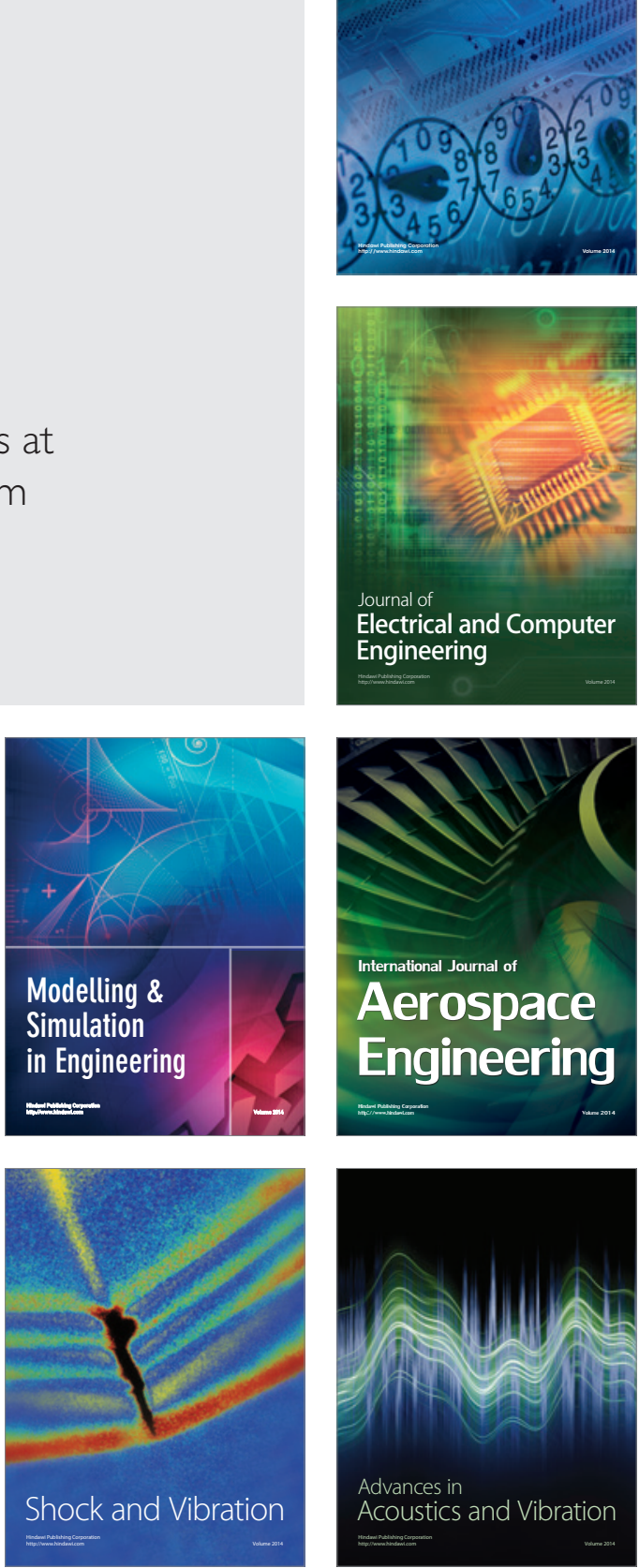